
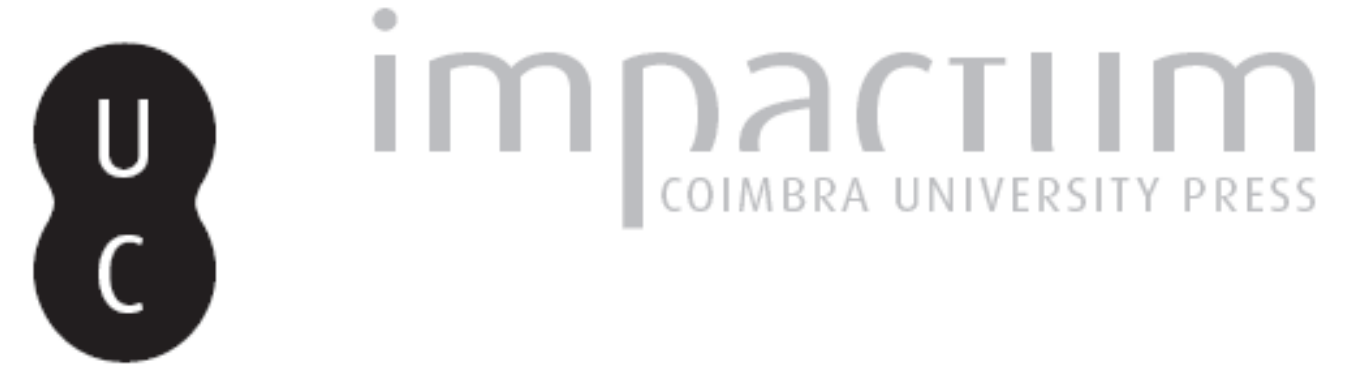

\title{
Oração de Cataldo em Bolonha
}

Autor(es): $\quad$ Ramalho, A. Costa; Silva, Augusta Fernanda Oliveira e

Publicado por: Faculdade de Letras da Universidade de Coimbra

URL persistente:

URI:http://hdl.handle.net/10316.2/32719

DOI:

DOI:http://dx.doi.org/10.14195/0870-4112_7_6

Accessed : $\quad$ 26-Apr-2023 12:42:31

A navegação consulta e descarregamento dos títulos inseridos nas Bibliotecas Digitais UC Digitalis, UC Pombalina e UC Impactum, pressupõem a aceitação plena e sem reservas dos Termos e Condições de Uso destas Bibliotecas Digitais, disponíveis em https://digitalis.uc.pt/pt-pt/termos.

Conforme exposto nos referidos Termos e Condições de Uso, o descarregamento de títulos de acesso restrito requer uma licença válida de autorização devendo o utilizador aceder ao(s) documento(s) a partir de um endereço de IP da instituição detentora da supramencionada licença.

Ao utilizador é apenas permitido o descarregamento para uso pessoal, pelo que o emprego do(s) título(s) descarregado(s) para outro fim, designadamente comercial, carece de autorização do respetivo autor ou editor da obra.

Na medida em que todas as obras da UC Digitalis se encontram protegidas pelo Código do Direito de Autor e Direitos Conexos e demais legislação aplicável, toda a cópia, parcial ou total, deste documento, nos casos em que é legalmente admitida, deverá conter ou fazer-se acompanhar por este aviso.

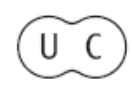




\section{Sociedade em Tumulto}

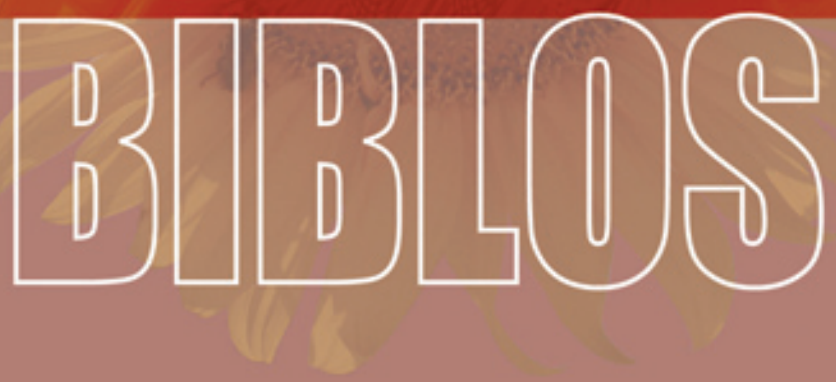

REVISTA DA FACULDADE DE LETRAS

UNIVERSIDADE DE GOIMBRA 
Biblos, n. s. VII (2009) 119-148

\author{
A. Costa Ramalho \\ Augusta Fernanda Oliveira e Silva \\ Universidade de Coimbra
}

\title{
ORAÇÃO DE CATALDO EM BOLONHA
}

\section{Resumo}

O elogio da Universidade de Bolonha é o primeiro do género publicado em Portugal. O discurso terá sido pronunciado em Bolonha, em 1479, ou até antes, e foi impresso em Lisboa no primeiro volume da correspondência de Cataldo, em 1500. Os elogios das universidades portuguesas, Lisboa e Coimbra, chegados até nós, foram impressos nos anos trinta do século XVI, em Lisboa, e posteriormente, em Coimbra. De maior interesse é o louvor da cidade de Bolonha, rica de recursos, famosa pela sua generosidade, nomeadamente, pelo acolhimento a refugiados das guerras de Itália, da fome e da peste. Particularmente privilegiados são os estudantes, de quem Cataldo chega a dizer que os habitantes de Bolonha por eles dariam a vida, se fosse necessário. Tal não era corrente nas relações entre estudantes e habitantes locais de outras cidades universitárias.

Palavras-chave: humanistas, elogios de universidades, Bolonha, Lisboa, Coimbra.

\section{Abstract}

The speech in praise of the University of Bologna is the first of its kind to have been printed in Portugal. This speech may have been delivered in Bologna, in 1479, or even before, and it was printed in Lisbon in the first volume of Cataldo's epistles, in 1500. The speeches in honour of the Portuguese universities (Lisbon and Coimbra) that have reached us, were printed in the third decade of the 16th century in Lisbon, and later in Coimbra. Of greater interest is the eulogy of the town of Bologna, rich in resources and famous for its generosity in receiving the refugees of the Italian wars, of famine and the plague. Especially favoured are the students, about whom Cataldo says that the city's inhabitants would give their own lives for them if need be. This was not the case in most university towns.

Keywords: humanists, speeches in praise of universities, Bologna, Lisboa.

$$
\begin{array}{l|l}
\text { Faculdade de Letras } & \text { Universidade de Coimbra }
\end{array}
$$




\section{PREFÁCIO}

Cataldo Parísio Sículo a quem, por um erro cometido no final do século XVI, também incluíram no nome o apelido de Áquila ${ }^{1}$, não diz quando foi pronunciada a sua Oratio, nem por iniciativa de quem, se da Universidade de Bolonha, se da própria cidade. Limita-se a empregar o advérbio publice, publicamente.

Já alguém escreveu que a Oração foi pronunciada em 1500 . Trata-se de um lapso evidente pois foi impressa em Lisboa em 1500, mas pronunciada em Bolonha antes da vinda de Cataldo para Portugal em 1485.

$\mathrm{Na}$ sua correspondência (Ep. I, diij), o humanista diz que à Oração assistiu o famoso jurista André Barbazza que muito apreciou a eloquência do jovem orador. André Barbazza era siciliano como Cataldo, e gozava do maior prestígio no meio universitário bolonhês. Ora, Barbazza faleceu a 21 de Julho de 1479. Tendo Cataldo nascido em 1455, teria 24 anos quando pronunciou o seu discurso ou talvez menos ainda. Aliás, Cataldo afirma, no próprio texto da sua Oratio, que era então adulescens, qualificativo que em latim pode aplicar-se a um homem até 30 anos.

O elogio da Universidade e da cidade de Bolonha pertence a um género corrente na época, a propósito das cidades universitárias.

Eram pronunciados estes panegíricos normalmente na abertura do ano lectivo, que se efectuava, no século XV e começo do século XVI, a dezoito de Outubro, dia de São Lucas. Mais tarde, na terceira década do século XVI, ou talvez ainda antes, a abertura solene das aulas foi antecipada para 1 de Outubro, dia de São Remígio. Isto pelo que diz respeito à universidade portuguesa, quer em Lisboa, quer, mais tarde, em Coimbra.

Entre nós, a obrigação de pronunciar a oração inaugural pertencia ao lente de Teologia que podia fazer-se substituir por um latinista de boa reputação, mesmo que este não fosse professor da universidade. Foi o que aconteceu com o conde de Alcoutim (1504), com André de Resende (1534), e com Jerónimo Cardoso (1536), todos na Universidade de Lisboa. Quanto à idade do orador, note-se que, se Cataldo era jovem, jovem também era o seu discípulo, D. Pedro de Meneses, quando em 18 de Outubro de 1504, pronunciou a sua Oratio na Universidade de Lisboa, pois tinha 17 anos de idade.

${ }^{1}$ Cf. A. Costa Ramalho, "Cataldo", Para a História do Humanismo em Portugal, IV, Lisboa, 2000, p.33-48.

Faculdade de Letras | Universidade de Coimbra 
Estas orações de sapiência continham ampla exemplificação de citações de autores gregos e latinos, especialmente de $\mathrm{Cícero}^{2}$, repetidas com frequência. Assim, não é de estranhar que reminiscências da Oratio de Cataldo em Bolonha se encontrem naquela que pronunciou Hilário Moreira na Universidade de Coimbra em 1 de Outubro de $1552^{3}$.

Estas orações continham o elogio das disciplinas professadas na Universidade, e, ocasionalmente, daqueles que as professavam. De um modo geral, as disciplinas eram sumariamente referidas, mas os oradores alongavam-se, por vezes, um pouco mais, nas da sua especialidade. Assim, não é difícil notar que Cataldo era um jurisconsulto. Com efeito, doutorou-se nos dois Direitos, Pontifício e Civil, na Universidade de Ferrara, e não de Bolonha - como é corrente ler-se - em 21 de Fevereiro de $1484^{4}$. No ano seguinte, veio para Portugal, onde faleceu cerca de 1517 , tendo assim vivido mais tempo no nosso país do que em Itália.

\section{ORATIO HABITA BONONIAE PUBLICE A CATALDO IN OMNIUM SCIENTIARVM ET IN IPSIVS BONONIAE LAVDES.}

Philosophia inuentum uel (ut ait Plato) deorum donum e caelo in terras elapsa, quantum boni comodique mortalibus attulerit, non solum ego minimus adulescens adhuc, sed ueteres quoque oratores enarrando deficerent, siquidem ut omittam cetera haec nos primum ad deorum cultum; deinde ad ius hominum quod situm est in generis humani societate, tum ad modestiam, magnitudinemque animi erudiuit. Eademque ab animo tanquam ab oculis caliginem dispulit, ut omnia superiora, infera, prima, media, ultima uideremus. Igitur non immerito tot philosophi totque sapientissimi uiri ad eam inquirendam excolendamque non mediocriter elaborarunt. De cuius laudibus, si non satis idonee dixero, nemo profecto mirari poterit.

Quis enim dubitat, exiguam cymbana, quae per uastum mare, immensumque Oceanum soluerit, plerumque huc et illuc errantem

${ }^{2}$ Cf. A. Costa Ramalho, "Cícero, nas Orações Universitárias do Renascimento", Para a História do Humanismo em Portugal, I, Coimbra, 1988, p.31-47.

${ }^{3}$ Cf. Albino de Almeida Matos, A Oração de Sapiência de Hilário Moreira, Coimbra, INIC/CECH, 1990.

${ }^{4}$ Cf. G. Pardi, Titoli dottorali conferiti dallo studio di Ferrara nei secc. XV e XVI, Lucca, 1900, p.12-13. 
esse perituram? Quare quomodocumque potero, rem ipsam adoriar, et bipartito nostra diuidetur oratio.

Nam et de omnibus facultatibus quae in his florentissimis studiis perpetuo exerceri solent, non particulatim, sed summatim quam breuissime fieri poterit, aliquid attingam; deinde ad excellentiam amplitudinemque huius antiquissimae urbis paululum me conuertam.

Haec est illa omnium artium mater, quae nihil aliud est nisi studium sapientiae. Sapientia autem diuinarum humanarumque rerum et causarum, quibus haec res continetur scientia. Haec est illa quae rerum initia causarumque, et rerum naturam aperuit. Haec est illa quae uarios sphaerarum motus multarumque rerum obscuritatem, et admirandos siderum cursus mortalibus patefecit. Haec agrestes ac rudes homines morem ferarum uagantes, in urbes conuocauit et ad deorum cultum sanctamque religionem redegit et instituit. Haec modum ac rationem bene et beate recteque uiuendi edocuit. Haec quantum amicis, cognatis, parentibus ac patriae deberemus, monstrauit.

Vnde et Cicero ad eam se conuertens dixit: «O uitae philosophia dux! O uirtutis indagatrix expultrixque uitiorum! Quid non modo nos, sed etiam uita hominum sine te esse potuisset? Tu urbes peperisti. Tu dissipatos homines in uitae societatem conuocasti. Tu inuentrix legum, magistra morum et disciplinae fuisti.

Magna nimirum haec res est, sapientissimi uiri, quae et praeteritos et praesentes quique nobis futuri sunt aduersi casus, facile ipsa tolerari facit. Miserias namque omnes paupertates, inopias, calamitates, denique quicquid aduersi hominibus euenire potest, sola haec patientissime ac constantissime facit nos perferre.

Nonne is qui philosophiae munitus est praeceptis intolerabiles dolores, ipsam etiam mortem, et si quid uideretur aut grauius, aut taetrius contemnit, et prorsus nihil facit?

Testis est quantum faciat philosophia, sapientissimus ille Socrates, qui quanta animi constantia condemnatus falso scelere ad mortem, uenenum hauserit! Eius oratio a Platone antea relata, a Cicerone postea comprobata plane id ostendit. In qua praesentibus iudicibus asserebat nihil sibi melius euenisse quam mitteretur ad mortem, exoptans quoque si fieri potuisset saepe uelle emori. Quod nisi philosophiae praeceptis fuisset tantus uir subleuatus, nunquam se in ipsa praesertim morte, tam fortiter gessisset.

Ea enim facit ut homo sit minimis contentus rebus, et ut omnem animi mollitiem omnesque inanes cupiditates resecet, et ad sublimes cogitationes traducatur. Accedunt praeterea ad hanc nobilissimam 
facultatem, ornatissimae eius filiae, qualis est musica, geometria et aliae quoque clarissimae artes ac facultates.

Et ut de musica prius loquar, quid de ea nunc dicam? Quae tanti fuit olim apud ueteres, ut qui illius fuisset ignarus, quamuis ceterarum rerum peritus, indoctus tamen a nonnullis putaretur. Nam et Themistocles cum se lyrae imperitum fateretur - ut testis est Cicero - habitus est indoctior, siquidem non ad uoluptatem tantum erat apta res haec, sed ad excitandos in proeliis exercitus plurimum apud ueteres ualebat.

Atque etiam tubarum et tibiarum sonos non in conuiuiis modo ac scenis sed in funeribus quoque et mortuorum exequiis moris fuit ueteribus adhibere, ut in his carminibus facundissimus uates ostendit:

«Temporibus ueterum tibicinis usus auorum

Magnus, et in magno semper honore fuit.

Cantabat fanis, cantabat tibia ludis,

Cantabat maestis tibia funeribus».

Geometria et arithmetica, quarum altera in terrae coelique spatiis metiendis, altera in numerorum ratione demonstranda consistit, quantam delectationem, non sine multarum rerum cognitione afferunt?

Grammatica uero quot et quantos fructus pariat, satis sit una Quintiliani auctoritas quo minus inquit ferendi sunt qui hanc artem ut tenuem ac ieiunam cauillantur. Quae nisi oratoris futuri fundamenta fideliter iecerit, quicquid superstruxeris, corruet. Necessaria pueris, iucunda senibus, dulcis secretorum comes! Et quae uel sola omni studiorum genere plus habeat operis quam ostentationis.

Quid de poetica sine qua multa fortissimorum uirorum clarissima gesta perirent?Quam quantum laudis semper meruerit summorum uirorum et primum Alexandri Magni testimonio iudicemus: qui inter spolia Darii Persarum regis unguentorum scrinio capto quod erat auro gemmisque ac margaritis pretiosum uarios eius usus amicis demonstrantibus - quando taedebat unguenti bellatorem et militia sordidum - «Immo, hercle inquit - librorum Homeri custodiae detur». Idem Pindari uatis familiae penatibus quem iussit parci, cum Thebas inuaderet. Idemque Alexander cum in Sigeo ad Achillis tumulum astitisset: «O fortunate - inquit adulescens, qui tuae uirtutis praeconem Homerum inuenisti!»

Sed quid prior Africanus? Nonne Quinti Ennii statuam suo sepulchro imponi iussit, ut ipse quoque una cum poetae titulo legeretur?

Quid diuus Augustus an? Non Virgilii carmina contra eius testamentum cremari uetuit? 
Parua haec fortasse quibusdam uideri possent. At Socrates quid apud Platonem in eo libello, cui De Iade, siue Ion est titulus, de poetis censet? Nonne omnis bonos poetas studiose legendos esse existimat?

Oratoria uero facultas suis cumulata dotibus, non nisi in bonis uiris esse potest. Ea est quae gloriosos homines extollat, effrenatis moderetur, innocentes absoluat, segnes ac timidos erigat, et ad omnia ardua cuiusuis animum promptissimum conuertat. Quae res Demosthenis exemplo facilis est confirmatu, quippe solus ipse Athenienses in Philippum Macedonum regem, quamuis in se concitos, irritauit. Hinc per omnem Graeciam legatus cunctas fere Graecas ciuitates in Philippum dicendo commouit.

Et ne plura de Graecis loquar, quanta in Cicerone dicendi uis emicuit! In causa enim Quinti Ligarii quae apud Caesarem dictatorem agebatur, fertur Caesar eo animo fuisse, ut omnino Ligarius esset condemnandus; et cum uenisset defensurus Cicero, dixit Caesar amicis: «Reum quidem damnare certissimum est; audire tamen Ciceronem nihil prohibet».

Sed pulchrum est nunc referre quid illo deinde agente contigerit. Incipit iam Cicero tunc dicere. Audiebat Ciceronem Caesar, sed nihil adhuc exordio illo mouebatur. At ubi Cicero aliquanto uehementius in dicendo incaluit, adeo Caesar ui illa dicendi commotus est, ut statim condemnandi propositum mutaret, totoque excusso corpore, libellos quos manu tenebat prae indignatione eiiceret, et reum Ciceronis oratione coactus eo momento liberaret.

Quid pro Lucio Flacco? Quid pro Murena? Nonne eos uario crimine accusatos, atque multorum testimoniis conuictos, ac propterea iamiam mulctandos ipse Cicero dicendo liberauit?

Contra quid in Lucium Verrem? Quid in perniciosissimum Publium Clodium? Quid in Marcum Antonium fecit? Quid etiam in audacem ac temerarium Catilinam? Eum etenim urbem Romam exurere parantem non repressit modo, sed perfregit et funditus extinxit.

Et licet de oratoriae laudibus hoc in loco plura haberem dicenda, ueritus tamen ne in ea facultate, cui me adscripserim, ambitiosus uidear, ea relicta, ad astrologiam uenio, quae non parum laudis, tam apud uetustissimos quam recentiores sibi uendicauit.

Ea enim non nunquam praeter admirabiles elementorum effectus, et praeter uarios siderum cursus, aliarumque rerum subtilitatem, futurarum quoque rerum euentus praenoscit.

Dialectica uero quae non modo naturalium, et earum quae sunt supra naturam sed omnium rerum rationes praebet, quanta laude extollenda est! Quae suis quibusdam argutiis ita proponit et concludit, 
ut non modo uerum ex falso sed falsum ex uero, si uoluerit, ostendat. Atque nihil est quod aliter esse uideatur, quam ipsa probauerit, necnon se ad ipsam ueritatem redigens, omnibus dominatur. Eamque - dixit Cicero - uicinam esse ac finitimam eloquentiae scientiam. Vnde et Zeno ille a quo disciplina stoicorum est, manu demonstrare solebat quid inter has artes interesset. Nam cum compresserat digitos pugnumque fecerat eiusmodi dialecticam esse aiebat; cum autem pugnum diduxerat et manum dilatauerat, palmae illius similem eloquentiam esse dicebat.

At medicina quantum prosit corporibus humanis, ex ipso experimento iudicare possumus. Non enim humanam, sed diuinam quandam uim in expellendis aegrotantium morbis uidetur habere. Quae adeo utilis est mortalibus, ut sine ea omnes paene corporis sui salutem prorsus desperarent. Ea tamen adhibita et bene administrata, ita adiuuantur aegroti, ut non ab hominibus, sed a diis opem se accepisse existiment.

Sed quid de sacra theologia loquar, in qua tota christiana fides tamquam in arce munitissima eminens ita uniuersos christianos ad diuinum cultum excitat, ut pro ea sanguinem quisque fundere, et hanc uitam perdere quam maxime contenderet? De cuius mirificis laudibus satius silentio pertransiri quam minimum attingi existimo, scio enim multos in hac parte praestantissimos uiros, altiora scrutantes, amissis mentis luminaribus caligasse.

Et ne diutius in his inmoremur, ad sacratissimas leges transeamus. In quarum laudibus efferendis nescio equidem unde prius exordiar; et si scio unde exordiar, ignoro tum ubi sit mihi de earum laudibus finis imponendus. Adeo argumentosa res est, ut quocumque te uerteris amplissimus undique dicendi campus tibi offeratur.

Hic, si fas esset, auxilium a diis immortalibus ausim implorare. Hic, hic, si fas esset, deorum omnium numen inuocare non uererer. Quis enim tanta esset feritate, qui non miris laudibus leges ipsas extolleret? Quae etsi e mediis philosophiae uisceribus fluxerint, ita tamen ad commoditatem generis humani excultae atque ordinatae sunt ut non aliter quam secundum earum praecepta esse nobis uiuendum censeamus.

Quid enim non perueteretur nisi leges ac iura quo pacto uiuere deberemus nos instruerent? Quid enim aliud quid nos agere, et a quibus rebus abstinere debeamus, ostendit? Parum certe aut nihil paene a brutis distaremus, si leges ac iura, quibus quid aequum quidue bonum sit continetur, non haberemus.

Namque hinc primum et mores optimi in matrimoniis ceterisque rebus contrahendis instituuntur. Et totius uitae ordo, qualis futurus 
sit, nascitur. Hinc uitiorum benefactorumque omnium censura inter mortales constituitur. Hinc irae, inimicitiae, odia, simultates, factiones, tumultus, proditionesque pacantur et corriguntur. Hinc furta, latrocinia, rapinae, uiolentiae, astutiaeque et quaeuis ceterae fraudes seuerissime puniuntur. Hinc si quid immodeste aut inofficiose, uel tale quid siue in rem publicam, siue in quos non liceat, esse factum constiterit, rectissime coercetur et multatur.

Denique tanta sunt seueritate ipsae leges, ut ne iis quidem, qui eas condiderunt si flagitiose uixissent ullo unquam pacto pepercissent.

Magistratus quoque in imperio iurisdictioneque aliqua constituti si in reddendo iure male se gesserint, nulla saepe habita differentia non leuiter puniuntur, ut inde ceteri omnes qui futuri sunt magistratus, recta lance quod aequum, quodue bonum sit, administrent.

Vnde ad hoc illud Titi Manilii Torquati in Decium Syllanum iudicium adduci potest. Nam cum apud patrem de Decio Syllano filio Macedones prouinciales quererentur, quod eis contra ius pecunias extorserat, cognita prius causa, et domo sua et patria protinus eum priuauit. Inde filius ob tam grauem patris sententiam, laqueo se suspendit.

Adde etiam Lucii Bruti memorabile facinus, qui cum in consulatu curare de reuocandis in urbem regibus liberos suos comperisset, eos in forum adduxit, et media contione uirgis caesos securi percuti iussit.

At cum Seruilius Hala magister equitum Spurium Melium quaedam noua contra leges molientem interfecisset, et quidam immerito interfectum esse quererentur, pronuntiauit dictator, aduocata multitudine, iure occisum Melium etiamsi nihil contra leges commisisset, quando uocatus a magistro equitum ad dictatorem non uenisset.

Illum uero memorandum magis est, quod nisi in ueteribus historiis esset traditum, nonnullis fortasse incredibile uideretur. Seleucus Locrensis ut suis pareret legibus ciuium precibus aliqua ex parte uolens satisfacere, petentium, ut filio suo pro commisso adulterio condemnando parceret, uoluit prius suum, deinde filii oculum tollere. Talis enim erat legis poena ut utrumque oculum adulter perderet.

Plura ego de hac re haberem dicenda, nisi in claris auctoribus essent latius pertractata.

Eoque magis inter ceteras facultates leges ipsae extollendae sunt, quae non ab hominibus, sed a diuino aliquoesse eas compositas credamus. Quam enim admirabilis in proponendis casibus latet subtilitas? Et in decidendis illis quam inest concinna praessaque breuitas? Rursus in ipsa breuitate quanta diluciditas emicat? Quanta quoque uerborum non 
sine grauibus sententiis redundat proprietas? Tandem nihil elegantius, nihil sublimius artificiosiusue, ac melius iurisconsultorum oratione apud quosuis auctores legitur.

Quam ob rem, etsi a iurisconsultis multa et praeclara dicta, de ipsarum legum laudibus reperiam, ne tamen quae de semet ipsis iurisconsulti bene senserint, afferam, uideamus quaedam quae inter plura alia de his, Marcus Tullius dixerit his uerbis: «Siue quem ista prepotens et gloriosa philosophia delectat - dicam audacius - hosce habet fontes omnium disputationum suarum quae in iure ciuili et legibus continentur. Ex his enim dignitatem maximam expetendam uidemus. Tum uero et iustus ac honestus labor honoribus, praemiis, splendore decoratur. Vitia autem hominum atque fraudes, damnis, uinculis, ignominiis, uerberibus, exiliis, morte multantur. Et docemur - non infinitis concertationumque plenis disputationibus, sed auctoritate nutuque legum - domitas habere libidines, coercere omnes cupiditates, nostra tueri, ab alienis mentes, oculos, manus abstinere. Fremant omnes licet, dicam quod sentio. Bibliothecas, me hercle, omnium philosophorum unus mihi uidetur duodecim tabularum libellus, si quis legum fontes et capita uiderit, et auctoritatis pondere et utilitatis ubertate superare.

Sed quid ego haec commemoro? Ex multorum barbarorum moribus quantum prosint leges sanctaeque institutiones cognosci potest. Et ut taceam Lestrygonas et Cyclopas quid de ipsis Aegyptiis loquar, quorum tanta est amentia - quia sine legibus uiuunt - ut crocodillos et cercopythecos pro diis habeant et adorent? Estque in illis tanta feritas ut humana carne uesci non horrescant. De quo scelere uehementissimus poeta ille satyrus conqueritur his uersibus:

«Quis nescit, Volusi Bithynice, qualia demens

Aegyptus portenta colat? Crocodilon adorat

Pars haec, illa pauet saturam serpentibus ibim

Effigies sacri nitet aurea cercopitheci,

Dimidio magicae resonant ubi Menone chordae,

Atque uetus Thebe centum iacet obruta portis.

Illic caeruleos, hic piscem fluminis. Illic

Oppida tota canem uenerantur, nemo Dianam.

Porrum et caepe nefas uiolare ac frangere morsu.

$\mathrm{O}$ sanctas gentes quibus haec nascuntur in hortis

Numina! Lanatis animalibus abstinet omnis

Mensa. Illic fetum iugulare capellae,

Carnibus humanis uesci licet (...)». 
Africanae quoque gentes inter meridiem et occasum habitantes, quanta ducantur cecitate, ex earum prauis miserisque consuetudinibus discerni liceat. Quae adeo spurce et sordide uiuunt, ut ne bestiarum quidem similes eas esse dixeris. In coniunctione marium ac feminarum quod nos matrimonium appellamus adeo gentes illae effrenatae sunt, ut nulla habita consanguinitatis ratione, septenas uxores cuique illorum permittatur ducere.

O gentem barbaram! O gentem efferam, et ueri nesciam! Ita ne degeret, si legibus ac iuribus, qualia in optimis urbibus esse debent, uteret?

Adde etiam ius pontificium, ex quo non facile dictu sit quantas humanum genus commoditates suscipiat: non modo utilitatem publicam, sed animae ipsius salutem ante omnia spectat; et quia huius iuris uberrimi fructus plerisque innotuerunt, non nisi paucissima quaedam de eo hoc in loco referenda esse arbitror. Ex quibus intelligere poterimus quam bene apteque ecclesiam ipsam suis ordinibus ornauerit; quamue optimum uiuendi modum clericis ceterisque religiosis imposuerit. Quae omnia quam recte in iure pontificio pertractata sunt, haud facile dixerim; et ut in ceteris dignitatibus sic quoque in beneficiis impetrandis omnium cupiditates satis decenter per hoc ius refrenantur.

In ipso uero matrimonio eum seruauit ordinem, ut non aliter quam secundum illum esse nobis uiuendum uel haeritici ipsi prauaeque sectae homines arbitrentur. Vtque matrimonii bona seruarentur, prohibuit non sine exactissima poena, omnia per quae matrimonii fides uiolaretur.

Et quia facilius ad malas quam ad bonas flectimur actiones, magna cum seueritate usurarium crimen exercerit uetuit. Nec minori sane seueritate ipsius ambitus crimen compescuit.

Illud uero multo praestantius fuit quod ita ad christianam fidem propagandam contra haereticos statuerit, ut ne animo quidem tale quid committere aliquis auderet. Et quam mitissime disposuerit poenas, quibus mali prauique afficiendi sunt, sanctissimae censurae id plane ostendunt.

De his autem rebus quae ad diuinum cultum, et de his quae ad ipsius animae salutem attinent, cum mirum in modum per se pateant, non puto esse aliquid dicendum. Ex his enim paucissimis, quae breuiter diximus considerare possumus, quantum humano generi ius pontificium conferat. Quare non parum, sapientissimi uiri, urbes quae optimis moribus optimisque institutis exornatae sunt, gaudere gloriarique possunt.

Hactenus de philosophia ceterisque nobilissimis facultatibus non nihil diximus; nunc per ipsius Bononiae laudes aliquantulum euagemur. 
Quae ut in litteris omnium urbium clarissima celebratur, sic quoque in rerum abundantia fertilitateque, nec minus in aeris temperie, et in sui ipsius pulchritudine, praestantissima extollitur. Neque id immerito.

Non enim desunt per omnem huius felicissimae urbis agrum planicies amoenissimae, non prata omni tempore uirentia, non montes et colles, non ualles, non flumina ab auctoribus admodum celebrata, non siluae tot arboribus opacissimae, et id genus permulta alia pro locorum dispositione decentia.

Quae omnia ab alto Deus ad Bononiensium uoluptatem, commoditatemque pro eorum probitate uidetur concessisse.

At in armis et in omnibus rebus bellicis non parum laudis urbs haec olim sibi uendicauit, tum propter uiros quos habuit fortissimos, tum quod uincere hostem semper fuerit assueta.

De qua re, etsi multa et egregia ad confirmationem hanc possim adducere - quod tamen uelle illa commemorare longissimum esset potest quicumque uidendi ea studio tenetur, in annalibus chronicisque urbis huius inquirere.

Sed quid de huius urbis liberalitate in alendis, nutriendisque tot pauperibus totque inopibus loquar? Erant quidem in hac urbe multi tam ciues quam externi pauperes. Deinde increscente iam paulatim in prouintia annonae penuria, plures huc quam primum conuenerunt; neque ob hoc urbs haec benignissima in alendis illis indignabatur. Anno tamen ab hinc uno cum per totam regionem magis, magisque increuisset rerum omnium inopia, centeni millenique pauperes ad hanc urbem aduolabant. Nec Pisas, nec Florentiam, aut Ferrariam petebant. Sed Bononiam tanquam omnium rerum matrem quae facile ac libenter opem omnibus praestare soleat, concurrebant. Nec tantum - modo mares, sed etiam feminae cum suis infantibus atque pueris simul uenerunt. Suntque illis omnibus quam primum constituta praeter uetera, noua quoque receptacula, multum illis idonea. Ex quibus receptaculis alia commodiora sunt recipiendis eis, qui ualidiori prosperiorique essent corpore. Alia uero his parata sunt, qui si morbo aliquo laborarent, illuc se reciperent. Hoc itaque pacto felicissimus quisque illorum sibi uidetur, et pro Bononiensibus nunquam precari desinit.

Quid ergo miramur si urbs haec in maxima tranquilitate iamdiu acquieuerit?

Quid ergo miramur, si neque fame neque peste, neque aliquo casu fortunae sit unquam opressa?

Quid ergo miramur, si de hac urbe ferantur prouerbia illa «Bononia fertilis», «Bononia scientiarum omnium ac legum mater» cum tot 
officiis ex omni parte tam in deos quam in homines cumulatissime profluentibus abundet?

Haec est igitur illa caritas, haec est, inquam, erga deos illa pietas, haec est illa religio, quae in hoc saeculo felicitatem in dies Bononiensibus adaugeat, post obitum uero beatitudinem aeternamque fruitionem afferet. Nulla sunt enim tam parua in deos beneficia - modo bona rectaque uoluntate fuerint oblata - quae non optimam remunerationem, uel in uita, uel saltem post uitam sint susceptura. Et quamquam urbs haec Bononia olim apud ueteres Felsina appellata sit, postea tamen non sine magno rerum argumento Bononiam cognominatam esse credimus. Quo uocabulo usus his uerbis expressit Suetonius: «Nero patri gratias in Senatu egit; apud eumdem consulem pro Bononiensibus latine, pro Rhodiis atque Iliensibus graece uerba fecit». Plinius quoque dixit Titum Fallonium Bononiensem centum et quinquaginta uixisse annos.

Qua propter quanta laude, quanta gloria urbs haec celeberrima digna sit, ex hoc in primis consideremus quod in ea omnium rerum probatissimi ac peritissimi uiri iamdiu floruerunt et in dies certatim insurgunt. Et ut ueteres taceam, quid recentiorum doctrinam humanitatemque opus est commemorem qui quanta sint erga studentes beneuolentia ceterasque nationes nemo est qui ignoret? Non modo bona ac diuitias exponerent, sed - quod incredibilius est - uitam ipsam pro studentibus effunderent.

Quot, inquam, in philosophia doctores in hac urbe excellunt? In astrologia et in sacra pagina, ac medicina, quantos possem clarissimos commemorare! In legibus uero ac iure pontificio peto a uobis, uiri sapientissimi, ubi doctiores, excellentioresque quam in hac urbe reperiri poterunt.

Nonne ita bene leges ceteraque iura legunt, enucleant, decidunt, emmendant et corrigunt, ut non interpretari, sed denuo condere illa existimentur?

Nolim in referendis laudandisque omnium doctorum uirtutibus dicendi modum excedere. Quisque suo exactissimo iudicio singularique prudentia singulorum praestantiam perpendat et iudicet. Et quae uobis in praesentia refero, maiora experimento ipso reperiet.

$\mathrm{Nec}$ immerito ab extremis orbis regionibus ad haec florentissima studia omne hominum genus quotidie confluit. Et degens diutissime saepe ob excellentiam huius clarissimae urbis domicilium hic perpetuum sibi constituit.

Desunt fortasse Studiis Bononiensibus studentes Theutones, Daci, Insubres, Ligures, Pisani, Florentini, Senenses, Perusini, Romani, Neapolitani, Calabri Lucani, Apuli, Siculi, Hispani, Balearici, 
Sardi, Gallo, Hunni, et alii complures quos singulos fastidiosum esset connumerare, non uerentes bona ac patriae commoda horum studiorum nomine perpulsi deserere. An niues, an pluuias, an imbres, rigidissimaeque frigora horrescunt?

$\mathrm{Nec}$ pudet me mei ipsius testimonium licet nihili adducere. Poteram ego nuper, ut omnes fere sciunt, sub Ferdinando Neapolitano rege non cum minimo stipendio degere; audito tamen huius urbis nomine, ita excitatus incalui, ut omnibus relictis commoditatibus, ad eam incolendam uenirem. In qua non breui quidem tempore, si Deus fauerit, uitam peragam.

Non tacebo etiam id quod nos ipsi cum de multis Italiae urbibus scriberemus, de Bononia quoque in libello nostro hoc modo inseruimus:

«De te quid memorem, summarum gloria rerum

Sacrarumque parens antiqua Bononia legum,

Quam Pallas Mauorsque potens coluisse feruntur,

Quamque ipse ante alios habitauit Iupiter aequus.

Hic pietatis opus colitur studiumque bonorum.

Quidue Astraea iubet, uel quicquid mandat honestas.»

Posset nihilominus aliquis me increpans dicere: «Nonne sunt in Italia doctores clari, studiaque minime obscura praeter Bononiensia? Nonne sunt quam plurima?»

Absit a me hoc tale nefas quod non dicere modo, sed ne cogitare quidem auderem. Scio enim doctores celebres esse multos, studia etiam multa praeter Bononiensia in Italia clarere non dubito. Sed si quis illa cum Bononiensibus Studiis uolet comparare, minora illa infimaque et nullius esse pretii uidebit.

Quid dicam? In tam amplum sublimemque splendorem studia haec elata sunt, ut nemo licet doctissimus foret, rerum ullarum peritus a quoquam crederetur, nisi breui saltem tempore, in his studiis fuisset uersatus. Non desunt praeterea hic in omni disserendi genere quotidianae exercitationes approbatissimaeque contentiones, quo fit ut disserentium ingenia reddantur acutiora, doctrina augeatur; uires quoque inde non mediocres sumantur. Et ut alter altero emulatione quadam superior certamine discedat summopere annituntur. Quod genus exercitii adeo Aristoteli summo philosopho probatum est, ut quotidie matutinis sophiam postmeridiani autem scholis rhetoricam praeciperet, noto illius huiusmodi graeco prouerbio: «Escron siopan che Isocratin ean legin» 
«turpe est tacere et Isocratem pati.» Tantaque fuit Isocrati lectionum contentionumque publicarum cupiditas, ut in scholis octauum et xc annum moriens dicatur expleuisse.

Quas ob res cum tot optimis disciplinis, totque scientiis nobilissimis non sine doctoribus, tam ueteribus quam recentioribus praeclarissimis haec urbs admodum praefulgeat; cumque etiam rerum omnium magnificentia atque abundantia tanquam totius orbis regina emineat; et cum in rebus bellicis potentissima inuictissimaque prae ceteris glorietur; et cum in deorum cultu quantum diuina ratio expostulat, sanctissima peruigilet; cumque propter optimos, religiosissimosque ciues beatissima existat, nihil certe superest aliud, nisi Summum Patrem quoad possumus pia mente semper et ubique precemur, ut ipsam Bononiam cum sua gente, uosque, magnificentissimi uiri, felicissime ac beatissime in aeternum conseruet. Finis.

\section{ORAÇÃO PUBLICAMENTE PROFERIDA EM BOLONHA POR CATALDO, EM LOUVOR DE TODAS AS CIÊNCIAS E DA PRÓPRIA BOLONHA}

A Filosofia - invenção ou (como diz Platão) presente dos deuses, descido do céu à terra - quanto de bom e de útil trouxe aos mortais, não só eu, na minha insignificância, ainda adolescente, mas também os antigos oradores não deixariam de explicar visto que, para omitir outros argumentos, ela primeiramente nos ensinou o culto dos deuses; depois, o direito dos homens que está estabelecido na comunidade do género humano; depois disso, a moderação e a grandeza de alma. E a mesma dispersou as trevas do espírito, tal como as dos olhos, de modo que pudéssemos ver todas as coisas: as superiores, as inferiores, as primeiras, as intermediárias e as últimas ${ }^{5}$. Por isso, não sem razão, tantos filósofos e tantos homens prudentes se aplicaram, não moderadamente, a investigá-la, a cultivá-la. De seus louvores, se eu não falar de modo bastante conveniente, ninguém, em verdade, poderá admirar-se.

Quem, pois, duvida de que há-de perder-se uma pequena barca que tenha soltado a vela pelo vasto mar e imenso oceano, quase sempre errando por aqui e por ali? Portanto, como quer que possa, abordarei o assunto, e a nossa oração em duas partes se dividirá.

Com efeito, de todas as disciplinas que, nesta florentíssima universidade, perpetuamente costumam ser cultivadas, algo direi, não

${ }^{5}$ Cf. Cícero, Tusculanae Disputationes, I, 26, 64. 
em pormenor, mas genericamente, com a brevidade possível; depois, voltar-me-ei, um pouco, para a excelência e para a grandeza desta antiquíssima cidade.

Esta é aquela famosa mãe de todas as artes que nada mais é senão o estudo da Sabedoria. A Sabedoria, por sua vez, é a ciência das coisas divinas e humanas e das causas nas quais esta virtude se contém ${ }^{6}$. Foi ela que revelou os inícios das coisas e a natureza das causas e das coisas. Foi ela que desvendou aos mortais os vários movimentos dos corpos celestes e a obscuridade de muitas coisas, e os admiráveis percursos dos astros. Foi ela que chamou às cidades os homens rústicos e rudes que vagueavam à maneira das feras, e os instruiu no culto dos deuses e da santa religião. Foi ela que ensinou o modo e a regra de bem viver, com justiça e felicidade. Foi ela que mostrou quanto devíamos aos amigos, aos parentes, aos antepassados e à pátria.

E, por isso, também Cícero, voltando-se para ela, disse: “Ó Filosofia, condutora da vida! Ó investigadora da virtude e expulsadora dos vícios! Que é que, sem ti, não só nós, mas também a vida dos homens podia ter sido? Tu geraste as cidades. Tu chamaste à comunhão de vida os homens dispersos. Tu foste a inventora das leis, tu foste a mestra dos costumes e da disciplina"7.

Esta é, sem dúvida, ó homens sábios, uma realidade importante que, por si mesma, faz que suportemos facilmente as adversidades passadas e presentes e as que estão para nos acontecer. É que infortúnios, todas as pobrezas, privações, calamidades, enfim, tudo o que de adverso aos homens pode acontecer, só ela faz que toleremos com toda a paciência e firmeza.

Porventura, esse que está fortalecido com os preceitos da Filosofia não despreza dores intoleráveis, até a própria morte, e mesmo algo que pareça mais grave e mais terrível que a morte, e tem isso absolutamente em conta nenhuma?

Testemunha é de quanto faz a Filosofia aquele sapientíssimo Sócrates, o qual, condenado à morte por um falso crime, com quanta firmeza de ânimo engoliu o veneno! E o seu discurso, relatado primeiramente por Platão e, depois, comprovado por Cícero, claramente o mostra. Nesse discurso, na presença dos juízes, afirmava que nada de melhor lhe poderia acontecer do que ser enviado para a morte, desejando também, se tal pudesse ser, querer morrer muitas vezes. E se

\footnotetext{
${ }^{6}$ Cf. Cícero, De Officiis, II, 2, 5.

${ }^{7}$ Cf. Cícero, Tusculanae Disputationes, V, 2, 5.
} 
um homem de tanto valor não estivesse sustentado com os preceitos da Filosofia, nunca se comportaria com tanta coragem, sobretudo na sua própria morte.

De facto, a Filosofia faz que um homem se contente com pequenas coisas, e que suprima toda a moleza de espírito e todos os vãos desejos, e se eleve a sublimes reflexões. Além disso, juntam-se a esta nobilíssima disciplina as suas prestigiosas filhas, como são a Música, a Geometria e também outras ilustres artes e disciplinas.

E, para falar, primeiramente, de Música, que direi dela agora? Que foi outrora, de tanto valor entre os antigos que aquele que dela fosse ignorante, ainda que perito nas restantes matérias, assim mesmo, por alguns seria considerado ignorante. De facto, até Temístocles, ao confessar-se inábil na lira, foi considerado ignorante, como Cícero é testemunha ${ }^{8}$, visto que esta arte não se destinava apenas ao prazer, mas entre os antigos valia muitíssimo para excitar os exércitos nas batalhas.

E também esteve nos costumes antigos aplicar os sons das tubas e das flautas não só nos banquetes e espectáculos, mas também nos funerais e nas exéquias dos mortos, como nos seus poemas mostra um eloquente poeta :

«Nos tempos dos antigos avós, o uso das flautas

Foi grande, e tido sempre em grande honra.

Soava a flauta no templo, soava nos jogos.

Soava a flauta nos tristes funerais.»

A Geometria e a Aritmética, das quais uma consiste em medir os espaços da terra e do céu, a outra, em demonstrar a razão dos números, quanto prazer trazem, não sem o conhecimento de muitas coisas!

Mas a Gramática, quantos e quão grandes frutos gera, baste só a autoridade de Quintiliano, segundo o qual não devem ser aceites aqueles que troçam desta arte como ligeira e vazia. E esta, se não tiver estabelecido fielmente os alicerces do futuro orador, tudo o que por cima se construir ruirá. Necessária aos meninos, agradável aos velhos, doce companheira da solidão! E ela, até sozinha, em todo o género de estudos pode ter mais efeito que ostentação ${ }^{10}$.

\footnotetext{
${ }^{8}$ Cf. Cícero, Tusculanae Disputationes, I, 2, 4.

${ }^{9}$ Cf. Ovídio, Fasti, 6, 607-610.

${ }^{10} \mathrm{Cf}$. Quintiliano, De Institiutione Oratoria, 1, 4.
} 
E que dizer sobre a Poesia, sem a qual muitos feitos ilustres de valorosos varões se perderiam? E quanto louvor sempre ela mereceu de varões excelsos, podemos julgar, citando em primeiro lugar o testemunho de Alexandre Magno: entre os espólios de Dario, rei dos Persas, tendo sido capturado o cofre dos perfumes, que era de grande valor em ouro e pedras preciosas, mostrando-lhe os amigos as suas várias utilidades - visto que os perfumes repugnavam a um homem guerreiro e sujo do combate - ele disse: «Antes, por Hércules, seja destinado à guarda dos livros de Homero». O mesmo, ao invadir Tebas, ordenou que poupassem a casa da família do poeta Píndaro ${ }^{11}$. E o mesmo Alexandre, estando em Sigeu, junto do túmulo de Aquiles, disse: «Ó afortunado jovem, que encontraste em Homero um pregoeiro do teu valor! ${ }^{12}$ »

E então o primeiro Africano? Não mandou que no seu sepulcro fosse colocada a estátua de Quinto Énio, para que ele próprio também fosse lido juntamente com a inscrição do poeta ${ }^{13}$ ? E o divino Augusto? Não proibiu que fossem queimados os poemas de Virgílio, contrariando o testamento deste? Talvez estas coisas possam, a alguns, parecer ligeiras. Mas Sócrates que pensa dos poetas, em Platão, naquele opúsculo, que tem por título Da Iónia, ou Íon? Não é ele de opinião de que se devem ler atentamente todos os bons poetas ${ }^{14}$ ?

Quanto à faculdade Oratória, cumulada de todos os seus dotes, não pode existir senão em homens bons. Ela é tal que exalta os varões gloriosos, modera os desenfreados, absolve os inocentes, excita os apáticos e tímidos e instiga prontamente o ânimo de quem quer que seja a todas as tarefas difíceis. E esta afirmação é fácil de se comprovar com o exemplo de Demóstenes, pois que ele, sozinho, contra Filipe, rei dos Macedónios, agitou os Atenienses, apesar de amotinados contra si próprio. Por isso, como enviado por toda a Grécia, moveu quase todas as cidades gregas, discursando contra Filipe ${ }^{15}$.

E, para não falar mais dos Gregos, quanta força oratória brilhou em Cícero! De facto, na demanda de Quinto Ligário, que era advogada na presença de César diz-se que César estava em tal disposição que absolutamente Ligário deveria ser condenado; e tendo vindo Cícero

${ }^{11}$ Cf. Plínio, Naturalis Historia, 7, 29.

${ }^{12}$ Cf. Cícero, Pro Archia, X, 24.

${ }^{13}$ Cf. Cícero, Pro Archia, IX, 22.

${ }^{14}$ Íon, nome de um rapsodo de Éfeso, que é interlocutor de Sócrates sobre a poesia, no diálogo homónimo.

${ }^{15} \mathrm{Cf}$. Plutarco, Demosthenes, 22, 1, 2, 3. 
para o defender, disse César aos amigos: «Seguramente, condenar o réu é inevitável; contudo, nada impede ouvir Cícero».

Mas belo é agora referir o que aconteceu depois de ele ter falado. Já começa então Cícero a falar. César ouvia Cícero, mas nada ainda mudava com aquele exórdio. Quando, porém, Cícero se empolgou, falando com um pouco mais de veemência, a tal ponto César se comoveu com aquela força oratória que, de repente, mudou o desígnio de condenar e, sacudindo todo o seu corpo, lançou fora, encolerizado, a sentença que tinha na mão e, impelido pelo discurso de Cícero, naquele momento libertou o réu ${ }^{16}$.

E na defesa de Lúcio Flaco? E na de Murena? Porventura, o mesmo Cícero, ao discursar, não libertou esses homens sujeitos a variadas acusações e vencidos pelos testemunhos de muitos, e por isso, quase já em risco de condenação?

E inversamente, contra Lúcio Verres? E contra o perigosíssimo Públio Clódio? E que fez ele contra Marco António? E ainda contra o audacioso e temerário Catilina? Com efeito, quando este se preparava para incendiar a cidade de Roma, não só o impediu Cícero, mas destroçou-o, e por completo, o aniquilou.

E ainda que dos louvores da Oratória eu tivesse mais coisas a dizer neste lugar, todavia, receando que, nesta faculdade em que me inscrevi, eu pareça pretensioso, pondo-a de parte, passo à Astrologia, a qual para si reclamou não poucos louvores, tanto entre os antigos, como entre os modernos. De facto, além dos efeitos admiráveis dos elementos, e além dos vários percursos dos astros, e da subtileza de outras coisas, ela por vezes também conhece, antecipadamente, os eventos futuros.

Quanto à Dialéctica, que não só mostra as razões do que é natural e daquilo que é sobrenatural, mas também de todas as coisas, com quanto louvor não deve ser exaltada! Ela que, com algumas argúcias suas, de tal modo propõe e conclui que, se quiser, mostra não só o verdadeiro a partir do falso, mas também o falso a partir do verdadeiro. E nada há que pareça de modo diferente do que ela própria provou, e também voltando à mesma verdade, a todos domina. E a Dialéctica - disse Cícero - é uma ciência vizinha e próxima da Eloquência. Por isso, também aquele famoso Zenão que é origem da disciplina dos estóicos, costumava mostrar com a mão o que há de diferente entre estas artes. De facto, quando apertava os dedos e fechava o punho, ele afirmava que assim era a Dialéctica; quando, porém, desfazia o punho

\footnotetext{
${ }^{16}$ Cf. Plutarco, Cicero, 39, 3. 
e expandia a mão, ele dizia que a Eloquência era semelhante àquela palma da sua mão ${ }^{17}$.

E a Medicina, quanto ela é útil aos corpos humanos, pela própria experiência, podemos avaliá-lo. Com efeito, parece ter não a humana, mas certa força divina para expulsar as moléstias dos doentes. E de tal modo é útil aos mortais que, sem ela, quase todos desesperariam completamente da sua saúde. Todavia, tomada e bem administrada, a tal ponto os doentes são ajudados que eles julgam ter recebido auxílio não dos homens, mas dos deuses.

E que direi acerca da Sagrada Teologia, na qual toda a fé cristã, erguendo-se como numa fortaleza muito bem defendida, de tal modo excita ao culto divino todos os cristãos, que por ela qualquer um porfiaria, ao máximo, em derramar o sangue e em perder esta vida? E de seus admiráveis louvores, considero que é preferível passar-se em silêncio a neles tocar superficialmente, pois sei que nesta área, muitos varões notáveis, perscrutando mistérios profundos, faltando-lhes as luzes do espírito, ficaram às escuras.

E, para nesta matéria nos não determos por mais tempo, passemos às Leis Sagradas. E para erguer os louvores delas, não sei, na verdade, por onde primeiro começar; e se sei por onde começar, ignoro, por outro lado, onde me devo impor o fim desses louvores. A tal ponto é uma matéria difícil que, para onde quer que te voltes, se te oferece, de todos os lados, um amplíssimo campo para a oratória.

Aqui, se fosse lícito, eu ousaria implorar o auxílio dos deuses imortais. Aqui, aqui, se fosse lícito, eu não hesitaria em invocar o poder de todos os deuses. Quem, pois, seria de tanta rudeza que não exaltasse essas leis com extraordinários louvores? E as leis, embora emanando das entranhas da Filosofia, todavia, de tal modo foram cultivadas e dirigidas para vantagem do género humano que pensamos dever viver -se segundo os preceitos delas e não de outro modo.

Pois que é que não se corromperia se a lei e a justiça não nos instruíssem de que modo devíamos viver? Pois que outra coisa nos mostra o que devemos fazer e de que acções devemos abster-nos? Pouco, por certo, ou quase nada seríamos diferentes dos irracionais, se não tivéssemos a lei e a justiça, nas quais se contém aquilo que é justo, ou o que é bom.

$\mathrm{E}$, na verdade, daqui, antes de mais, se estabelecem também costumes excelentes na celebração de casamentos e de outros negócios.

\footnotetext{
${ }^{17}$ Cf. Cícero, Orator, 32.
} 
E nasce a ordenação da vida inteira, qual ela há-de ser. Daqui, se punem, com a maior severidade, furtos, latrocínios, rapinas, violências e astúcias, e quaisquer outras fraudes. Daqui, se corrige rectamente e se castiga tudo quanto de excessivo, ou ilegal, ou coisa semelhante se verificar ter sido praticado contra a República, ou contra aqueles a quem não é permitido.

Finalmente, são de tão grave severidade as mesmas leis que jamais, de modo algum, poupariam sequer àqueles que as fizeram, se tivessem vivido criminosamente.

Também os magistrados, constituídos no exercício do poder e de alguma jurisdição, se ao ministrarem a justiça, procederam mal, muitas vezes sem ser considerada diferença alguma, são punidos não levemente, para que, daí, todos aqueles que venham a ser magistrados, administrem, com balança recta, o que é justo e o que é bom.

Daí, a este propósito, pode ser aduzido aquele julgamento contra Décio Silano. De facto, como os habitantes da província da Macedónia se queixassem, perante o pai, contra o filho Décio Silano - porque lhes extorquira somas de dinheiro, contra o direito - feito primeiramente o julgamento, privou-o imediatamente da sua casa e da pátria. Em seguida, por causa de tão grave sentença do pai, o filho enforcou-se ${ }^{18}$.

Acrescenta ainda a memorável acção de Lúcio Bruto que, sendo cônsul, ao descobrir que seus próprios filhos tentavam chamar, de novo, os reis para a cidade, conduziu-os ao fórum e, no meio da assembleia do povo, ordenou que fossem vergastados e decapitados ${ }^{19}$.

Mas quando Servílio $\mathrm{Hala}^{20}$, comandante da cavalaria, matou Espúrio Mélio que maquinava certas inovações contra as leis, e alguns murmuravam que ele fora morto injustamente, o ditador, convocada a multidão, declarou que Mélio fora morto justamente, ainda que nada tivesse atentado contra as leis, pois que, chamado pelo comandante da cavalaria ao ditador, ele não viera.

Mas há um caso que deve ser mais digno de memória, o qual, se não fosse contado nas histórias antigas, a alguns talvez parecesse inacreditável. Seleuco de Locres, para obedecer às suas leis, querendo satisfazer, de algum modo, às preces dos cidadãos que lhe pediam perdoasse a seu filho que devia ser condenado por ter cometido adultério, quis em primeiro lugar tirar um olho seu, e em seguida o olho do filho.

\footnotetext{
${ }^{18}$ Cf. Cícero, De Finibus Bonorum et Malorum, 1, 7.

${ }^{19} \mathrm{Cf}$. Tito Lívio, Ab Vrbe Condita Libri XLV, 2, 5.

${ }^{20} \mathrm{Cf}$. Idem, ibidem, 4, 13, 14, 15.
} 
De facto, tal era o castigo da lei: que o adúltero perdesse ambos os olhos.

Mais teria eu para dizer a este respeito, se não tivesse sido largamente aprofundado em ilustres autores.E tanto mais devem ser exaltadas as mesmas leis entre as restantes faculdades, quanto julgamos que, não por homens, mas por alguém divino, elas foram compostas. Com efeito, quanta subtileza admirável se esconde no propor dos casos? E na decisão dos casos, quanta elegância e concisa brevidade se encontra? Por outro lado, nessa mesma brevidade, quanta clareza brilha! E também como transborda a propriedade das palavras, não sem graves reflexões! Enfim, nada mais elegante, nada mais sublime, ou mais engenhoso e melhor se lê em quaisquer autores do que o discurso dos jurisconsultos.

E por isso, embora eu encontre muitos e notáveis ditos de jurisconsultos, a respeito dos louvores das próprias leis, todavia para eu não citar o que os jurisconsultos pensam favoravelmente dessas mesmas leis, vejamos alguns pensamentos que, entre muitos outros, a respeito delas, Marco Túlio disse nestas palavras: "Se há alguém a quem essa influente e gloriosa filosofia deleita - direi audaciosamente - esse tem estas fontes de todas as suas disputas que se contêm no direito civil e nas leis. Nós vemos, com efeito, que delas ele deve alcançar a dignidade máxima. Então também o trabalho justo e honesto será galardoado com honras, prémios e esplendor. Por outro lado, os vícios dos homens e as fraudes são punidos com danos, prisões, ignomínias, açoites, exílios e morte. E seremos instruídos - não com controvérsias inumeráveis e cheias de disputas, mas com a autoridade e a concordância das leis - a dominar os desejos sensuais, a refrear todas as cobiças, a defender as nossas coisas, a manter afastadas as mentes, os olhos e as mãos, das alheias. Murmurem todos, embora, direi o que penso. O opúsculo das Doze Tábuas, só por si, se alguém vir as causas e as origens da lei, parece-me, por Hércules, que supera, em peso de autoridade e em abundância de utilidade, as bibliotecas de todos os sábios" 21 .

Mas porque é que faço menção disto? A partir dos costumes de muitos bárbaros, pode conhecer-se quanto são úteis as leis e as sagradas instituições. E, para não falar dos Lestrigões e dos Ciclopes, que direi dos próprios Egípcios, cuja loucura é tão grande - porque vivem sem leis - que têm por deuses crocodilos e macacos de cauda, e

\footnotetext{
${ }^{21}$ Cf. Cícero, De Oratore, 1, 43-44.
} 
os adoram? E neles existe tanta barbárie que não se arripiam de comer carne humana. E deste crime aquele arrebatado poeta satírico se queixa nestes versos:

Quem ignora, ó Vóleso da Bitínia, que monstros venera o insensato Egipto? Ao crocodilo adora-o Uma parte, outra receia a íbis saciada de serpentes. Brilha a estátua de ouro do sagrado macaco, onde, a meio de Mémnon, cordas mágicas soam, e a velha Tebas jaz em ruínas com as suas cem portas. Ali, veneram os peixes do mar, aqui o peixe do rio. Ali, cidades inteiras veneram o cão, ninguém a Diana. Violar e partir com os dentes alho e cebolas é um sacrilégio. Ó santas gentes a quem nascem nos jardins tais divindades! Toda a mesa se abstém de animais cobertos de lã.

Ali é ímpio abater o filho da cabrinha, mas é lícito alimentar-se com carnes humanas ${ }^{22}$.

Também as nações africanas que habitam entre o sul e o ocaso, com quanta cegueira se conduzem, pode discernir-se a partir dos seus costumes viciosos e deploráveis. E elas vivem de modo tão obsceno e imundo que nem sequer se diria que elas são semelhantes aos animais. $\mathrm{Na}$ união de homens e mulheres, a que nós chamamos matrimónio, de tal modo aquelas gentes são desenfreadas que, sem nenhuma consideração de consanguinidade, é permitido, a cada um deles, casar com sete mulheres. Ó gente bárbara! Ó gente selvagem e ignorante da verdade! Assim viveria, se usasse as leis e o direito, tal como nas cidades civilizadas devem existir?

Acrescente-se ainda o Direito Pontifício, do qual não é fácil dizer-se quão grandes vantagens recebe o género humano: não só tem em vista a utilidade pública, mas, antes de tudo, a salvação da própria alma; e porque os frutos deste direito fecundíssimo se tornaram conhecidos da maior parte dos homens, penso que dele devem ser referidas, neste lugar, apenas poucas coisas. E de entre estas, poderemos compreender quão bem e convenientemente ele ornamentou a própria igreja com as suas disposições; como impôs um excelente modo de viver aos clérigos e restantes religiosos. E quanto todos estes assuntos foram aprofundados correctamente no Direito Pontifício, eu não saberia dizê-lo facilmente;

${ }^{22}$ Cf. Juvenal, Saturae, 15, 1-13. 
e como nas restantes dignidades, assim também nos benefícios a conseguir, as ambições são refreadas bastante decentemente por este Direito.

Por outro lado, no próprio matrimónio, o Direito Pontifício conservou esta ordem, a saber, que não devemos viver de outro modo senão de acordo com ele, ou então os mesmos serão considerados herejes e homens de errada seita. E para que os bens do matrimónio possam ser conservados, o mesmo Direito proibiu, não sem pesadíssimo castigo, tudo aquilo em que a fidelidade do matrimónio fosse ofendida. E porque mais facilmente somos inclinados às más do que às boas acções, com grande severidade proibiu que se exercesse o crime de usura. E, com não menor severidade, sabiamente reprimiu o crime de corrupção.

Por outro lado, foi muito mais útil aquilo que, para a expansão da fé cristã, estabeleceu contra os heréticos, por tal forma que, nem sequer em pensamento, alguém ousasse cometer tal erro. E com quanta suavidade legislou as penas com que os maus e perversos devem ser castigados, as santíssimas censuras claramente o mostram.

Ora, das coisas que dizem respeito ao culto divino, e das que respeitam à salvação da própria alma, visto que, de modo extraordinário, são por si evidentes, não julgo que haja algo que deva dizer-se. De facto, do pouco que brevemente referimos, podemos considerar quanto o Direito Pontifício convém ao género humano. Por esse motivo, ó sapientíssimos varões, as cidades que estão adornadas de excelentes costumes e excelentes instituições, podem, não pouco, alegrar-se e gloriar-se.

Até agora, dissemos alguma coisa acerca da Filosofia e das restantes nobilíssimas disciplinas; agora divaguemos um pouco pelos louvores da própria Bolonha. E ela, do mesmo modo que é celebrada como a mais ilustre de todas as cidades, nas Letras, assim também é exaltada como a mais notável na abundância e fertilidade dos bens, não menos na moderação do clima e na sua própria formosura. E não sem razão.

Com efeito, não faltam, por todo o território desta felicíssima cidade, planícies muito amenas, não faltam prados verdejantes em todo o tempo, não faltam montes e colinas, não faltam vales, não faltam rios muito celebrados pelos escritores, não faltam bosques espessos de tantas árvores, e do mesmo modo, não faltam muitíssimas outras coisas convenientes, segundo a disposição dos lugares. E tudo isto, parece que Deus o concedeu, lá do alto, para prazer e conforto dos Bolonheses, em recompensa da sua probidade. 
Mas nas armas e em todos os assuntos bélicos, outrora esta cidade reivindicou para si não poucos louvores, quer pelos homens muito corajosos que teve, quer porque sempre se acostumou a vencer o inimigo. E sobre esta matéria, embora eu possa aduzir muitos e excelentes exemplos para tal afirmação, todavia - porque querer recordá-los seria longuíssimo - todo aquele que é possuído pelo desejo de os ver pode pesquisar nos anais e crónicas desta cidade.

Mas que direi da liberalidade da cidade para alimentar e proteger tantos pobres e tantos carenciados? Havia, seguramente, nesta cidade, muitos pobres, tanto cidadãos, como estrangeiros. Em seguida, aumentando já sucessivamente na província a escassez de mantimentos, um maior número do que inicialmente afluiu aqui; nem por isso, esta cidade benigníssima se indignava por alimentá-los. Todavia, há um ano atrás, tendo aumentado mais e mais, por toda a região, a carência de todos os bens, centenas e milhares de pobres convergiam nesta cidade. Não procuravam Pisa, nem Florença, ou Ferrara. Mas corriam a Bolonha como a uma mãe de todas as coisas, que, facilmente e de boa vontade, a todos costuma prestar auxílio. E vieram, juntamente, não só homens, mas também mulheres com filhos de colo e crianças. E para todos foram estabelecidos, o mais cedo possível, além dos velhos, também novos abrigos, para eles muito convenientes. E de entre estes abrigos, outros há mais apropriados para receber aqueles que, fisicamente, fossem mais fortes e válidos. Outros, porém, foram preparados para que aqueles que, porventura, sofressem de alguma doença, aí se recolhessem. Por isso, deste modo, cada um deles se considera muito feliz e nunca cessa de rezar pelos Bolonheses.

Porque nos admiramos, então, de que esta cidade desde há muito tenha repousado na maior tranquilidade? Porque nos admiramos, então, de que ela não tenha sido alguma vez oprimida nem pela fome, nem pela peste, nem por qualquer outro acidente da fortuna? Porque nos admiramos, então, de que desta cidade se digam aqueles provérbios «Bolonha fértil», «Bolonha, mãe de todas as ciências e leis», quando ela abunda em tantos serviços que dimanam de toda a parte, tanto em favor dos deuses como dos homens?

Esta é, pois, aquela caridade, esta é aquela religião que, nesta vida, aumenta, de dia para dia, a felicidade dos Bolonheses e, depois da morte, trará a felicidade e a fruição eterna. De facto, não há benefícios tão pequenos para os deuses - contanto que tenham sido oferecidos com boa e recta intenção - que, ou nesta vida, ou pelo menos depois dela, não venham a receber excelente recompensa. $\mathrm{E}$, embora esta cidade de Bolonha tenha sido chamada outrora, entre os antigos, Félsina, mais tarde, 
todavia, não sem ponderosas razões, acreditamos que foi cognominada de Bolonha. Usando este vocábulo, com as palavras seguintes se expressou Suetónio: "Nero deu graças a seu pai no Senado; na presença do mesmo cônsul, ele discursou em latim a favor dos Bolonheses, e em grego a favor dos Ródios e dos Ilienses"23. Plínio também disse que Tito Falónio Bolonhês viveu cento e cinquenta anos ${ }^{24}$.

E, por isso, de quanto louvor e de quanta glória esta cidade celebérrima é digna, a este propósito, em primeiro lugar consideremos o facto de que, nela, desde há muito, têm florescido os homens mais experimentados e os mais conhecedores de todas as matérias, e todos os dias, à porfia, eles surgem. E para não falar dos antigos, que necessidade há de lembrar a cultura e a urbanidade dos presentes, os quais de quanta benevolência são para com os estudantes e as restantes nações, ninguém há que ignore? Não só ofereceriam os bens e as riquezas, mas - o que é mais incrível - dariam a própria vida pelos estudantes.

Digo eu: quantos doutores em Filosofia brilham nesta cidade? $\mathrm{Na}$ Astrologia e na Sacra Página e na Medicina, quantos muito ilustres eu poderia recordar! Mas, nas Leis e no Direito Pontifício, pergunto-vos, varões sapientíssimos, onde poderão ser encontrados homens mais doutos e mais excelentes do que nesta cidade? Não é verdade que de tal modo bem lêem, explicam, decidem, emendam e corrigem as Leis e o restante Direito, que se crê, não que interpretam, mas que de novo os constroem?

Eu não desejaria exceder a justa medida oratória ao referir e louvar as virtudes de todos os doutores. Pondere e julgue cada um, com o seu exacto discernimento e singular prudência, a superioridade de cada indivíduo. E aquilo que vos digo presentemente, pela própria experiência se descobrirá maior. E não sem razão, das regiões mais afastadas do mundo, cada dia, aflui a esta florentíssima universidade todo o género de homens. E habitando muito tempo, com frequência, por causa da excelência desta ilustre cidade, aqui estabeleceram domicílio perpétuo.

Porventura faltam à Universidade de Bolonha estudantes da Alemanha, da Dácia, da Lombardia, da Ligúria, de Pisa, de Florença, de Siena, de Perúsia, de Roma, de Nápoles, da Calábria, da Toscana, da Apúlia, da Sicília, da Hispânia, das Baleares, da Sardenha, da França, da Hungria, e muitos outros, que seria fastidioso enumerar um a um, que não receiam abandonar os bens e as comodidades da pátria, impelidos

\footnotetext{
${ }^{23}$ Suetónio, Vitae Caesarum, Nero, 7.

${ }^{24}$ Plínio, Naturalis Historia, 7, 49, 6.
} 
pela reputação desta Universidade? Acaso temem as neves, as águas das chuvas, os aguaceiros e os frios de enregelar?

E não me envergonho de aduzir o meu próprio testemunho, ainda que de pouco valor. Podia eu, há pouco tempo, como quase todos sabem, viver sob o patrocínio do rei Fernando de $\mathrm{Nápoles}^{25}$, com estipêndio não pequeno; todavia, ao ouvir a fama desta cidade, de tal modo me entusiasmei que, deixadas todas as comodidades, nela vim habitar. E nela, seguramente, se Deus me favorecer, viverei não por breve tempo, mas concluirei a vida.

Não calarei ainda aquilo que nós próprios, ao escrever acerca de muitas cidades da Itália ${ }^{26}$, também acerca de Bolonha incluímos no nosso opúsculo do seguinte modo:

«De ti, Bolonha, que recordarei, ó glória dos mais altos méritos,

E das sagradas leis mãe antiga,

Da qual se diz que Palas e o poderoso Marte habitaram,

E o próprio Júpiter, antes dos outros, habitou propício.

Aqui se cultivam as obras de piedade e o estudo do bem,

Ou o que Astreia ordena, ou seja o que for que a honra mande."

Poderia, entretanto, alguém dizer, censurando-me: "Porventura, não há, em Itália, doutores ilustres e universidades nada obscuras, além da bolonhesa? E não existem muitíssimas?'Longe de mim tal impiedade, que eu não só não ousaria dizer, mas nem sequer pensar. Sei, de facto, que há muitos doutores célebres e também não duvido de que muitas universidades, além da bolonhesa, brilham na Itália. Mas se alguém quiser comparar aquelas com a Universidade de Bolonha, verá que elas são menores, ínfimas e de nenhum valor.

Que posso dizer? Esta Universidade foi elevada a tão amplo e sublime esplendor que ninguém, ainda que fosse doutíssimo, seria geralmente acreditado como perito, se, ao menos por breve tempo, não se tivesse aplicado nesta Universidade. Além disso, não faltam aqui, em todo o género de discurso, exercícios quotidianos e discussões apropriadas, donde acontece que os talentos dos que dissertam se tornam mais ágeis, a ciência aumenta de dia para dia; também os recursos, por

${ }^{25}$ Fernando I, rei de Nápoles (1423-1494), filho natural de Afonso V, o Grande, rei de Aragão. Cf. Fernando Castelo Branco, Enciclopédia Verbo Luso-Brasileira de Cultura, Ed. Século XXI, Vol. 11, p. 1129.

${ }^{26}$ Este opúsculo de Cataldo, sobre as cidades italianas, não foi encontrado até hoje. 
esse motivo, se tornam superiores. E eles esforçam-se, com o maior empenho, com certa emulação, cada um por sair vencedor do outro. E este género de exercício de tal modo agradou a Aristóteles, filósofo de grande talento, que todos os dias, na escola da manhã, ensinava a Sabedoria, mas, da parte da tarde, ensinava a Retórica, sendo conhecido o provérbio grego dele: «Escròn siopãn kaì Isocratin eãn legin» ${ }^{27} \ll E$ vergonha ficar calado e deixar falar Isócrates». E tão grande foi o desejo de Isócrates de leituras e discussões públicas que se diz que ele acabou por morrer na escola com noventa e oito anos ${ }^{28}$.

E por estas razões, resplandecendo grandemente esta cidade com disciplinas tão excelentes, e tantos saberes nobilíssimos, não sem doutores ilustríssimos, tanto os antigos como os actuais; e sobressaindo ainda como rainha do mundo inteiro pela magnificência e abundância de todas as coisas; e gloriando-se, poderosa e invicta, à vista de outras, nos assuntos de guerra; e como ela vele com toda a santidade no culto dos deuses quanto a divina razão pede; e sendo ela felicíssima graças aos excelentes e piedosos cidadãos, nada mais resta senão que peçamos piamente, ao Sumo Pai, na medida das nossas forças, sempre e em toda a parte, que conserve Bolonha com sua gente, e a vós, magníficos varões, com a maior felicidade e ventura, eternamente.

${ }^{27}$ Cataldo escreve de acordo com a pronúncia do grego moderno, como era corrente no Renascimento.

${ }^{28}$ Cf. Quintiliano, De Institutione Oratoria, 3, 1 e Cícero, De Oratore, III, 35. 


\section{Bibliografia}

\section{Autores antigos:}

CICERO, Brutus. With an English translation by G. L. HENDRICKSON. Orator with an English translation by H. M. Hubbell, Harvard University Press, Loeb Classical Library, Cambridge, Mass., ${ }^{7} 1997$.

CICERO, De Oratore I-III, with an Introduction and Notes by Augustus S. Wilkins, Bristol Classical Press, 2002.

CICÉRON, M. T., Les Devoirs, livres II et III. Texte établi et traduit par Maurice Testard. Paris, Les Belles Lettres, 1970.

CICÉRON, Discours. Tome XII. Pour le poète Archias. Texte établi par Felix Gaffiot. Pour L. Flaccus. Texte établi par André Boulanger. Paris, «Les Belles Lettres», 1938.

CICÉRON, Tusculanes. Tome I. Texte établi par Georges Fohlen. Paris, «Les Belles Lettres», 1931.

CICERONIS, M. Tullii, De Finibus Bonorum et Malorum, Libri quinque, Nicolaus Madvigius recensuit et enarrauit, Georg Olms Verlagsbuchhandlung, Hildesheim, 1965.

JUVENAL, Satires. Texte établi et traduit par Pierre de LABRIOLLE et Francois VILLENEUVE, Douziéme tirage, revu, corrigé et augmenté par J. GÉRARD, Paris, «Les Belles Lettres», 1983.

LÍVIO, TITO, Tite-Live, Histoire Romaine, Paris, «Les Belles Lettres», 1940 e Tite-Live, Histoire Romaine, Paris, «Les Belles Lettres», 1946.

OVIDE, Les Fastes, Tome II, Livres IV-VI. Texte établi, traduit et commenté par Robert SCHILLING, Paris, «Les Belles Lettres», 1993.

PLATÃO, Íon. Introdução, tradução e notas de Victor Jabouille, Lisboa, Editorial Inquérito, 1988.

PLINE L'Ancien, Histoire Naturelle, Livre VII. Texte établi, traduit et commenté par Robert Schilling, Paris, «Les Belles Lettres», 1977.

PLUTARCO, Plutarch's Lives with an English translation by Bernadotte Perrin, VII, Demosthenes and Cicero, (...) Loeb Classical Library, Cambridge, Mass., ${ }^{6} 1971$.

QUINTILIEN, Institution Oratoire, tome II, livres II et III. Texte établi et traduit par Jean Cousin, Paris, «Les Belles Lettres», 1976.

SUÉTONE, Vies des Douze Césars, tome II. Texte établi et traduit par Henri Ailloud, Paris, «Les Belles Lettres», 1993.

Faculdade de Letras | Universidade de Coimbra 


\section{Cataldo Parísio Sículo:}

CASTELO BRANCO, Fernando, "Fernando I, rei de Nápoles", Enciclopédia Verbo Luso-Brasileira de Cultura, Ed. Século XXI, vol. 11, p.1129.

MATOS, Albino de Almeida, A Oração de Sapiência de Hilário Moreira, Coimbra, INIC/CECH, 1990.

PARDI, G., Titoli dottorali conferiti dallo studio di Ferrara nei secc. XV e XVI, Lucca, 1900.

RAMALHO, Américo da Costa, Para a História do Humanismo em Portugal, I, Coimbra, 1988.

RAMALHO, Américo da Costa, Para a História do Humanismo em Portugal, IV, Lisboa, 2000.

RAMALHO, Américo da Costa e SILVA, Augusta Fernanda Oliveira, "Cataldo Parísio Sículo, Provérbios", Ágora, 7, Universidade de Aveiro, 2005.

RAMALHO, Américo da Costa e SILVA, Augusta Fernanda Oliveira, Cataldo Parísio Sículo, Epístolas, II Parte, Lisboa, INCM, 2005.

RAMALHO, Américo da Costa e SILVA, Augusta Fernanda Oliveira, Cataldo Parísio Sículo, Epístolas, I Parte (no prelo). 